\title{
Modularidade e Custos: Seleção de Um Referencial para Pesquisa por Meio de Uma Análise Bibliométrica
}

Fabrício Eduardo Henriques

Mestrado em Engenharia Civil pela Universidade Federal de Santa Catarina - UFSC Engenheiro Civil na Universidade Federal de Santa Catarina - UFSC Campus Trindade. Trindade. Florianópolis/SC. CEP: 88.040-900 E-mail: fabricio_vp@hotmail.com

Paulo Maurício Selig Pós-doutorado em Engenharia de Produção pela Universidade Federal do Rio Grande do Sul - UFRGS Professor Associado da Universidade Federal de Santa Catarina - UFSC Campus Trindade. Trindade. Florianópolis/SC. CEP: 88040-900 E-mail: pauloselig@gmail.com

Paulo Augusto Cauchick Miguel Pós-Doutorado em Engenharia de Produção - National Institute of Standards and Technology Professor da Universidade Federal de Santa Catarina - UFSC Campus Universitário Trindade. Trindade. Florianópolis/SC. CEP: 88040-900

E-mail: cauchick@deps.ufsc.br

\section{RESUMO}

A modularidade é uma estratégia adotada por diversos setores industriais, seja no desenvolvimento de novos produtos ou na configuração produtiva industrial. Diversos são os aspectos que envolvem a modularidade, dentre eles os custos. Nesse contexto, este trabalho tem como objetivo realizar uma seleção de publicações referentes aos custos em desenvolvimento de produtos modulares por meio de uma análise bibliométrica sobre os autores e periódicos proeminentes do tema. O processo resultou em portfólio bibliográfico final de doze artigos relevantes e alinhados com o tema de pesquisa em quatro bases internacionais. $\mathrm{Na}$ análise bibliométrica foi avaliado $\mathrm{O}$ portfólio selecionado, os artigos mais relevantes, os autores, as palavras-chave e os periódicos que mais publicaram sobre o assunto em questão. Assim, podem-se verificar os artigos que mais se destacaram nessa área de modularidade sob a ótica da perspectiva de custos.

Palavras chave: modularidade de projeto, custo de desenvolvimento de produtos, bibliometria, custos.

Modularity and costs: selection of a reference for research through bibliometric analysis 
Modularidade e Custos: Seleção de Um referencial para pesquisa por Meio de uma Análise

Bibliométrica

Fabrício Eduardo Henriques, Paulo Maurício Selig, Paulo Augusto Cauchick Miguel

\section{ABSTRACT}

Modularity is a strategy adopted by various industrial sectors in new product development or in production configuration. Many aspects are related to modularity, and cost is one of them. In this context, this paper aims to perform a selection of publications with respect to the costs in modular design through a bibliometric analysis on authors and journals relevant in this subject. The final process resulted in twelve articles in the final portfolio. Those publications are relevant and aligned with the research subject found out in four bases. Most relevant articles, authors, keywords and journals that published most on the subject were evaluated by the bibliometric analysis in the selected portfolio. Therefore, it was possible to verify which papers stood out in the modularity subject within the cost perspective.

Key-words: modular design, development product costs, bibliometrics, project costs.

\section{INTRODUÇÃO}

Em um contexto geral de arquitetura de produto modular, Baldwin e Clark (1997) definem o conceito de modularidade como o processo de construir um produto complexo a partir de subsistemas de menor escala, que podem ser projetados independentemente, mas que funcionam como um todo. Os autores complementam que a modularidade é uma estratégia para organizar, eficientemente produtos e processos complexos.

Os principais tipos de modularidade encontrados na literatura são a modularidade de projeto ou de produto e a modularidade de produção ou de processos. A modularidade de projeto refere-se a uma estratégia de desenvolvimento de novos produtos na qual as interfaces entre os componentes compartilhados em uma determinada arquitetura de produto são especificados e padronizadas para permitir uma maior possibilidade de substituição dos componentes entre as famílias de produtos (MIKKOLA; GASSMAN, 2003). Já a modularidade de produção permite que os componentes de um produto sejam padronizados e produzidos de forma independente antes da montagem no sistema final (BALDWIN; CLARK, 1997).

Diversas publicações afirmam que a modularidade de produto tem efeitos positivos em várias dimensões do desempenho competitivo (FEITZINGER; LEE, 1997; FISHER 
Modularidade e Custos: Seleção de Um referencial para pesquisa por Meio de uma Análise

Bibliométrica

Fabrício Eduardo Henriques, Paulo Maurício Selig, Paulo Augusto Cauchick Miguel

et al., 1999; SUZIK, 1999; KUSIAK, 2002; TU et al., 2004). No entanto, dentre os diversos benefícios advindos da utilização da modularidade relacionados na literatura, há poucos estudos identificando os custos envolvidos na implantação de processos modulares ou no desenvolvimento de produtos, sendo este tema uma lacuna importante que demanda mais estudos tanto sobre os custos envolvidos como seus impactos em projeto e em produção (CAMUFFO, 2000).

Nesse sentido, o presente trabalho visa a busca, recuperação, organização e apresentação da literatura existente sobre o tema, identificando possíveis lacunas de pesquisa, para que trabalhos futuros sejam desenvolvidos. Busca-se então identificar publicações qualificadas que envolvam algum aspecto da gestão de custos, seja o custo de desenvolvimento de um produto modular, custo do ciclo de vida, análise de retorno de projetos (Payback, retorno de investimento - $\mathrm{ROI}$, etc.), impacto de projetos modulares em preços de ações, etc. A amplitude e dispersão do conhecimento em uma variedade de publicações e bases de dados dificulta a identificação de estudos relacionados a um determinado tema de pesquisa, relevantes do ponto de vista científico e alinhados com os objetivos dos pesquisadores que empreendem este trabalho, configurando-se em uma tarefa árdua e complexa (TASCA et al., 2010). Esta é uma situação que ainda segundo os autores citados, denota a relevância da utilização de um processo estruturado para este fim, no sentido de prover um quadro teórico robusto. Como objetivos específicos o trabalho pretende selecionar um portfólio bibliográfico relevante sobre a modularidade no contexto de custos e identificar por meio da análise bibliométrica do portfólio bibliográfico selecionado e de suas referências, os periódicos, artigos, autores e palavras-chave de destaque.

O presente trabalho é estruturado em cinco seções, sendo a primeira composta por esta introdução, seguida pela segunda que descreve os procedimentos metodológicos de pesquisa. A terceira seção apresenta ainda o processo de pesquisa nos bancos de dados para formar o portfólio bibliográfico. A quarta seção é composta pelos resultados da análise bibliométrica dos artigos do portfólio bibliográfico resultante 
Modularidade e Custos: Seleção de Um referencial para pesquisa por Meio de uma Análise

Bibliométrica

Fabrício Eduardo Henriques, Paulo Maurício Selig, Paulo Augusto Cauchick Miguel

e de suas referências. Por último, o trabalho apresenta as conclusões na sua última seção.

\section{PROCEDIMENTOS METODOLÓGICOS}

O presente trabalho pode ser classificado como teórico-conceitual, onde se enquadram as revisões de literatura. Seu propósito é levantar os principais trabalhos já realizados e disponibilizados sobre os temas (modularidade e custos), sendo estes tipos de trabalhos de grande importância (LAKATOS; MARCONI, 2006). Em função de seus objetivos, de avaliar as publicações existentes, o trabalho apresenta características exploratórias, conforme estabelecido por Gil (1999), que defende que um trabalho de pesquisa pode ser categorizado desse modo quando visa proporcionar maior familiaridade com um problema para torná-lo explícito ou a construir hipóteses. A natureza dos dados é predominantemente qualitativa (MINAYO et al., 2007), em termos de análise dos resultados, mas também considera uma representação dos dados quantitativa (FACHIN, 2005) utilizando gráficos para representação, bem como a estatística descritiva.

Lacerda (2011) coloca que diante da evolução dos sistemas de informações, o uso de base de dados bibliográficos (sistemas indexados) procura facilitar as buscas por referências relevantes, servindo de plataforma teórica para pesquisas futuras. Nesse sentido, trata-se de um processo de revisão bibliográfica, segundo uma visão construtivista, proposta por Ensslin et al. (2010). Este processo para a seleção de um portfólio bibliográfico é definido no processo subdividido nas seguintes fases, ilustrados na Figura 1 (ENSSLIN et al., 2010):

i) Seleção do banco de artigos brutos: composto pela definição das palavraschave, definição bancos de dados, busca de artigos nos bancos de dados com as palavras-chave e o teste da aderência das palavras-chave; 
Modularidade e Custos: Seleção de Um referencial para pesquisa por Meio de uma Análise

Bibliométrica

Fabrício Eduardo Henriques, Paulo Maurício Selig, Paulo Augusto Cauchick Miguel

ii) Filtragem: composta pela filtragem do banco de artigos brutos quanto a redundância e filtragem do banco de artigos brutos não repetidos quanto ao alinhamento do titulo;

iii) Filtragem do banco de artigos: composto pela determinação do reconhecimento cientifico dos artigos, identificação de autores;

iv) Filtragem quanto ao alinhamento do artigo integral: composto pela leitura integral dos artigos.

Selecionado o portfólio bibliográfico, é realizada então a análise bibliométrica dos artigos que o compõe. Uma análise bibliométrica é uma técnica para o mapeamento dos principais autores, periódicos e palavras-chave sobre determinado tema. $O$ emprego dessas técnicas de análise se apoia em uma base teórico-metodológica reconhecida, que possibilita o uso de métodos quantitativos para mapear informações, a partir de registros bibliográficos de documentos armazenados em bases de dados (MALDONADO et al., 2010). Esta análise ainda pode ser definida como um processo de evidenciação quantitativa de dados de um conjunto definido de artigos, denominado de portfólio bibliográfico, para a gestão da informação e do conhecimento científico de um dado tema, realizado por meio da contagem de documentos (ENSSLIN et al., 2010). Para a realização da análise bibliométrica são utilizados os artigos do portfólio bibliográfico e suas referências para apuração do grau de relevância de periódicos, grau de reconhecimento científico de artigos, grau de relevância dos autores e as palavras-chave mais utilizadas, como apresentado na Figura 2. 
Modularidade e Custos: Seleção de Um referencial para pesquisa por Meio de uma Análise
Bibliométrica Fabrício Eduardo Henriques, Paulo Maurício Selig, Paulo Augusto Cauchick Miguel

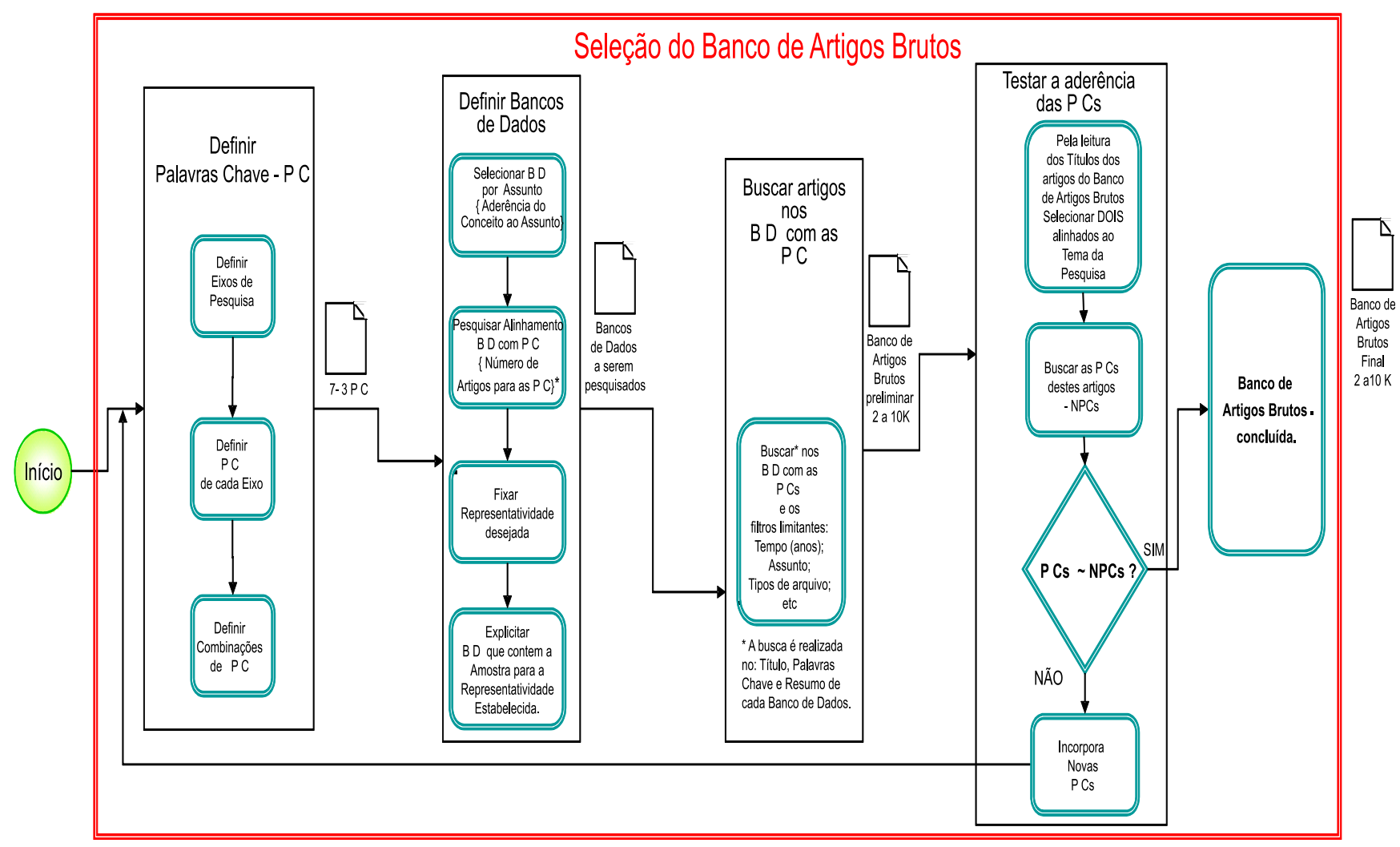

Figura 1 - Fases do processo de revisão bibliográfica segundo Ensslin et al. (2010). 
Modularidade e Custos: Seleção de Um referencial para pesquisa por Meio de uma Análise Bibliométrica Fabrício Eduardo Henriques, Paulo Maurício Selig, Paulo Augusto Cauchick Miguel

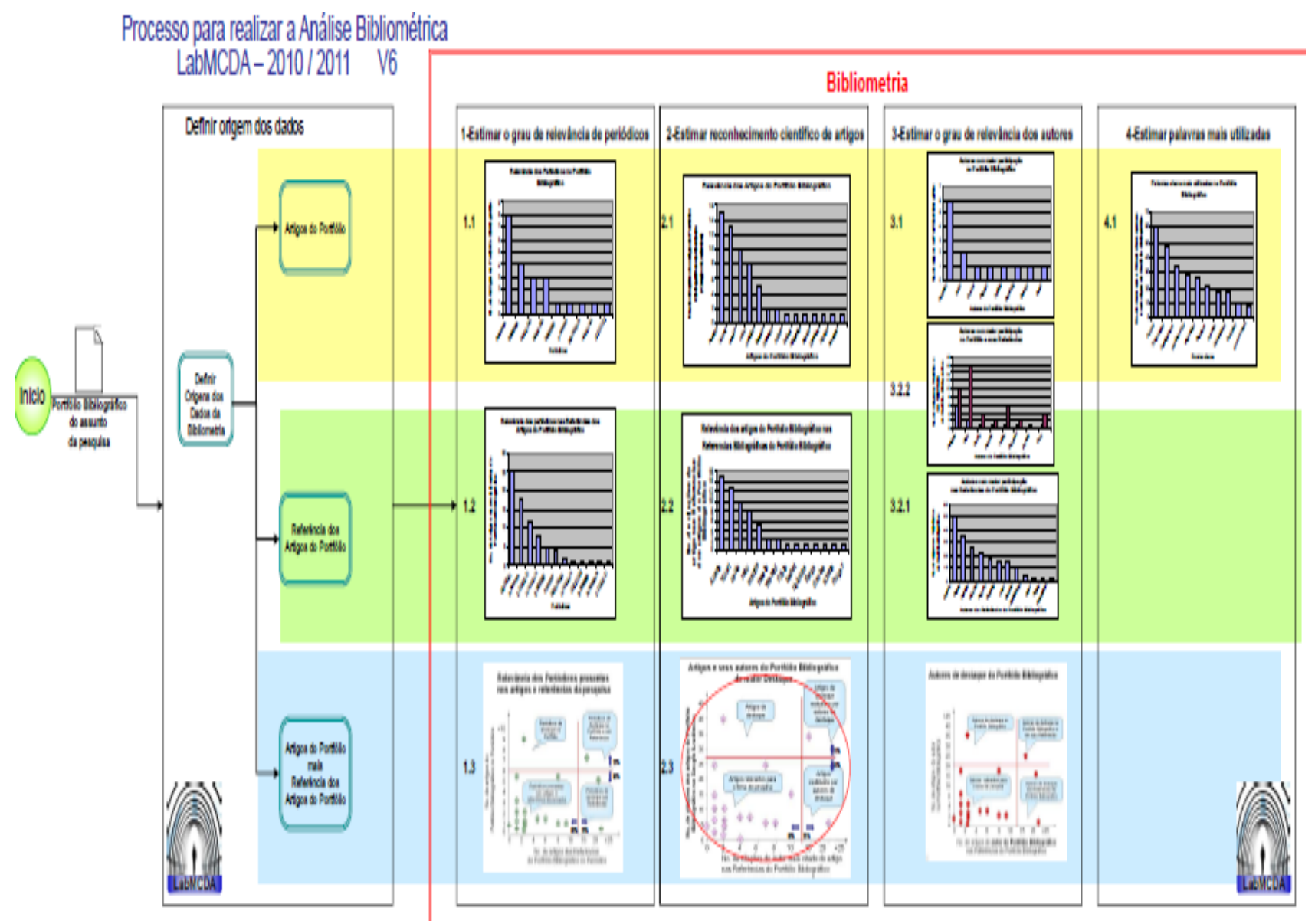

Figura 2 - Análise Bibliométrica (Fonte: ProKnow-C, Knowledge Development Process, 2010).

\section{PROCEDIMENTOS PARA SELEÇÃO DE REFERENCIAL TEÓRICO OU CONSTRUÇÃO DO PORTFÓLIO BIBLIOGRÁFICO RESULTANTE}

Para a construção do portfólio bibliográfico, os procedimentos foram divididos em três etapas que são detalhadas a seguir.

\subsection{Seleção do banco de artigos brutos}

Esta seção compreende a definição das palavras-chave e definição das bases de dados a serem utilizadas. 
Modularidade e Custos: Seleção de Um referencial para pesquisa por Meio de uma Análise Bibliométrica Fabrício Eduardo Henriques, Paulo Maurício Selig, Paulo Augusto Cauchick Miguel

\subsubsection{Definição das palavras-chave}

Em função de o trabalho ser alicerçado em dois temas, a definição das palavraschave (keywords) utilizadas para a seleção dos artigos brutos considerou aquelas aderentes aos temas "modularidade" e "custos". Como o tema central deste trabalho é a "modularidade" este é o primeiro tema utilizado. Tendo em vista que o tema se propõe a estudar o tema modularidade de projeto sob um enfoque da influência ou impacto dos custos, esta premissa orienta a necessidade de analisar o assunto sob a perspectiva de sua mensuração. O tema "custos" é, então, o segundo tema considerado no trabalho. $\mathrm{O}$ Quadro 1 apresenta as palavras-chave associadas a estes temas.

\begin{tabular}{|c|c|}
\hline MODULARIDADE & CUSTOS \\
\hline Modular Design & Product Development Cost $^{*}$ \\
\hline Modular Development Products & Project Cost $^{*}$ \\
\hline Modular Product Design & Design Cost $^{\star}$ \\
\hline Modularity & Management Cost $^{*}$ \\
\hline
\end{tabular}

Quadro 1 - Palavras-chave empregadas Fonte: desenvolvido pelos autores.

Para a consecução da busca de artigos alinhados sobre projetos modulares sob o enfoque da influência ou impacto dos custos, as palavras-chave escolhidas para os dois temas foram combinadas conforme ilustra a Figura 3. 
Modularidade e Custos: Seleção de Um referencial para pesquisa por Meio de uma Análise

Bibliométrica

Fabrício Eduardo Henriques, Paulo Maurício Selig, Paulo Augusto Cauchick Miguel
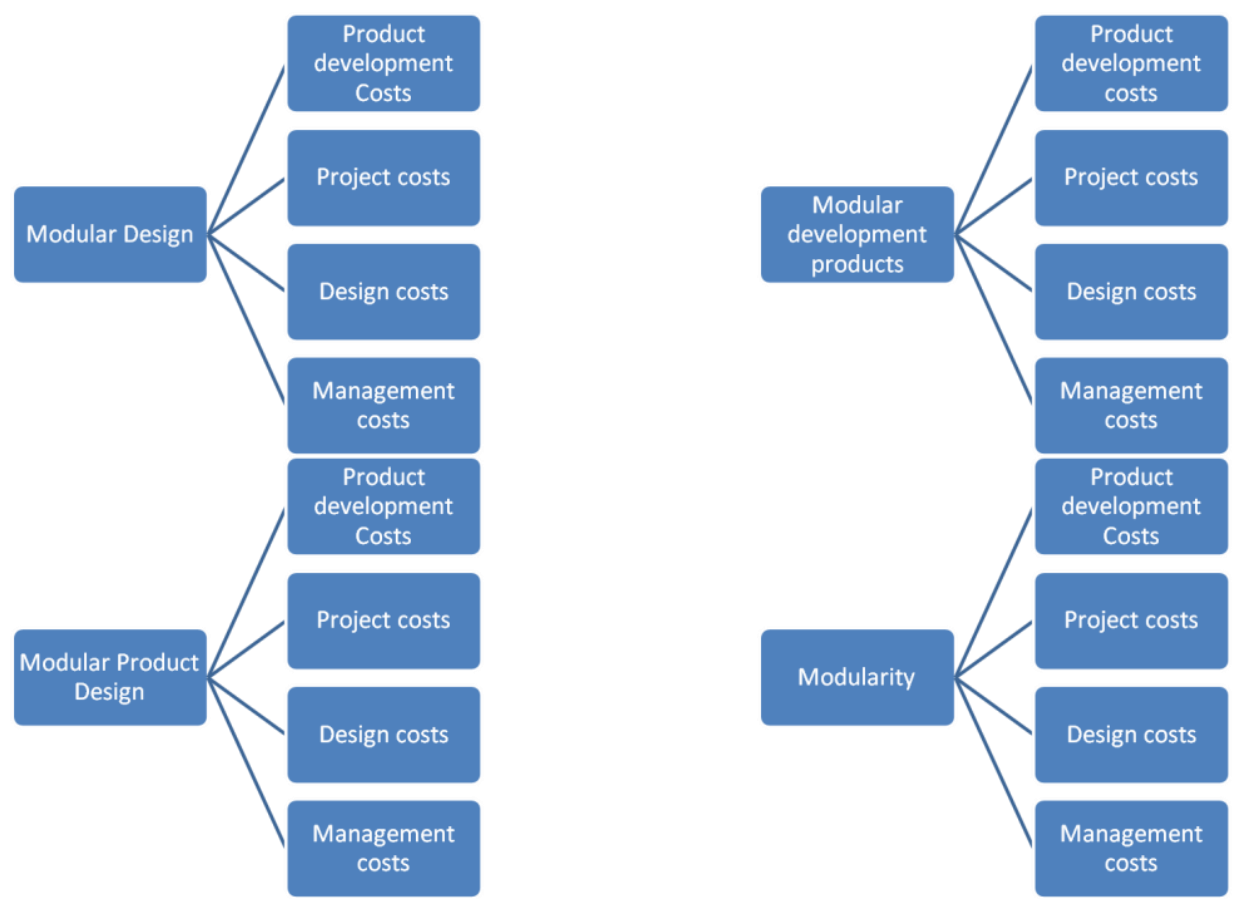

Figura 3 - Combinação das palavras-chave

Fonte: desenvolvido pelos autores.

Após a definição das bases de dados, cujo detalhamento é feito a seguir, e da seleção do banco de artigos brutos, foram identificados dois artigos (NEPAL et al., 2008 e WU et al., 2009) aderentes ao tema de pesquisa, sendo analisadas as palavras-chave utilizadas pelos autores para representar o assunto abordado em seus artigos. Isso foi realizado com o intuito de confirmar as palavras-chave definidas ou apontar a necessidade de alteração dessas palavras-chave e agregação de novas. Como resultados considerou-se que as palavras-chave escolhidas para o presente trabalho estavam adequadas e suficientes para representar o tema de pesquisa.

\subsubsection{Definição da Base de Dados}

Definidas as palavras-chave, foram selecionadas as bases de dados com acesso viabilizado pelo portal de periódicos da CAPES - Coordenação de Aperfeiçoamento de Pessoal de Nível Superior (CAPES, 2011). Na seleção das bases de dados considerouse seu alinhamento aos temas. Após a leitura da descrição de um total de 90 bases de 
Modularidade e Custos: Seleção de Um referencial para pesquisa por Meio de uma Análise

Bibliométrica

Fabrício Eduardo Henriques, Paulo Maurício Selig, Paulo Augusto Cauchick Miguel

dados (áreas: multidisciplinar - 19 bases; engenharias - 33 bases; ciências sociais aplicadas - 36 bases), 13 indicaram maior afinidade com os temas: Scopus; ScienceDirect (Elsevier); Emerald; Project Muse; Wiley Online Library; JSTOR Arts \& Sciences I Collection; Highwire Press; ISI Web of Knowledge; SpringerLink (MetaPress); ACM Digital Library; Academic Search Premier - ASP (EBSCO); Oxford Journals (Oxford University Press); e Cambridge Journals Online.

Assim, foi realizada a busca com o conjunto de palavras-chave em cada uma das 13 bases de dados. Esta atividade permitiu selecionar as quatro bases mais relevantes em relação ao tema, ou seja, com maior representatividade:

- Web of science: base multidisciplinar que indexa somente os periódicos mais citados em suas respectivas áreas. É também um índice de citações, informando, para cada artigo, os documentos por ele citados e os documentos que o citaram. Possui hoje mais de 9.000 periódicos indexados.

- Scopus: base de dados de resumos e de citações da literatura científica e de fontes de informação de nível acadêmico na Internet. Indexa mais de 15 mil periódicos, cerca de 265 milhões páginas da Internet, 18 milhões de patentes, além de outros documentos.

- Emerald: coleção de publicações periódicas com concentração nas áreas de Administração, Contabilidade, Ciência da Informação, Engenharia Mecânica, Engenharia Elétrica e Engenharia de Produção.

- Science Direct: estão disponíveis publicações da Elsevier e de outras editoras científicas, cobrindo as áreas de Ciências Biológicas, Ciências da Saúde, Ciências Agrárias, Ciências Exatas e da Terra, Engenharias, Ciências Sociais Aplicadas, Ciências Humanas e Letras e Artes.

A quantidade total de artigos encontrados nestas quatro bases de dados, considerando as combinações de palavras-chave e a delimitação temporal de 10 anos (2001 a 2011) e todos os tipos de arquivos disponíveis (livros, periódicos, conferências, etc.) foi de 5.974 itens, distribuídos conforme mostra a Figura 4. Cabe destacar que cada base de dados possui um sistema de busca particular. Assim, a configuração utilizada pelos autores para busca em cada uma dessas bases foi: 
Modularidade e Custos: Seleção de Um referencial para pesquisa por Meio de uma Análise Bibliométrica

Fabrício Eduardo Henriques, Paulo Maurício Selig, Paulo Augusto Cauchick Miguel

- Web of science: busca das palavras chave feita por "tópicos";

- Scopus: busca das palavras chave feita por "título do artigo, resumo e keywords";

- Emerald: busca das palavras chave feita utilizando a opção "all, except full text";

e

- Science Direct: busca das palavras chave feita por "título do artigo, resumo e keywords". O conjunto de artigos resultante dessas quatro bases passou a compor então o banco de artigos brutos.

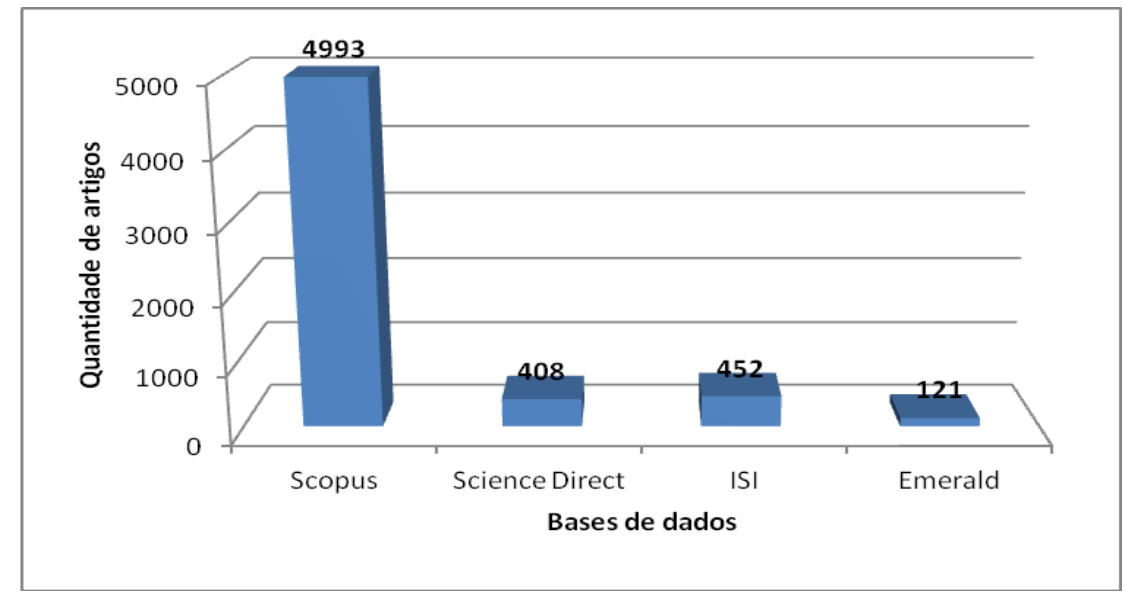

Figura 4 - Quantidade de artigos por bases

Fonte: desenvolvido pelos autores.

Como pode ser visto na Figura 4, destaca-se a base de dados Scopus com a maior quantidade de artigos no tema de pesquisa.

\subsection{Filtragens do banco de artigos brutos}

Esta seção descreve os processos de filtragem do banco de artigos bruto quanto à redundância e filtragem do banco de artigos brutos não repetidos quanto ao alinhamento do título. 
Modularidade e Custos: Seleção de Um referencial para pesquisa por Meio de uma Análise Bibliométrica Fabrício Eduardo Henriques, Paulo Maurício Selig, Paulo Augusto Cauchick Miguel

\subsubsection{Filtragem do banco de artigos brutos quanto à redundância}

As referências dos 5.974 artigos das quatro bases foram exportadas para um software de organização bibliográfica (Endnote). Considerando ainda que, muitas vezes, os artigos podem estar postados em mais de uma base ou relacionados a mais de uma combinação de palavras-chave, foi realizada a verificação de artigos duplicados no banco de dados bruto. Esta ação resultou na exclusão de 3.388 artigos duplicados.

\subsubsection{Filtragem dos artigos brutos não repetidos quanto ao alinhamento do título}

Esta filtragem refere-se da leitura dos títulos dos artigos para verificação do alinhamento destes com o tema desta pesquisa. A figura 5 apresenta as etapas realizadas.

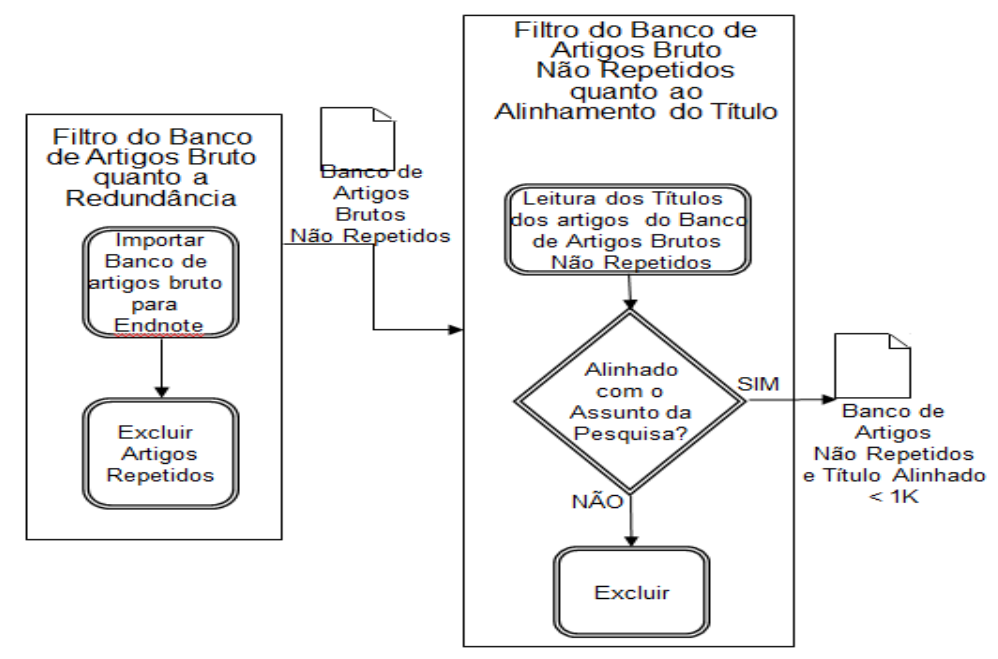

Figura 5 - Filtragem de artigos brutos quanto à redundância e alinhamento do título Fonte: ProKnow-C, Knowledge Development Process (2010).

O resultado dessa etapa foi de 2.586 artigos não repetidos a serem verificados, tendo como banco de dados final 72 artigos alinhados com o título ao tema de modularidade com a ótica de custos. 
Modularidade e Custos: Seleção de Um referencial para pesquisa por Meio de uma Análise

Bibliométrica

Fabrício Eduardo Henriques, Paulo Maurício Selig, Paulo Augusto Cauchick Miguel

\subsection{Filtragem do banco de artigos e alinhamento integral dos artigos}

A filtragem do banco de artigos inicia-se pela verificação do reconhecimento científico, utilizando o Google Scholar quanto ao número de citações, conforme as etapas mostradas na Figura 6.

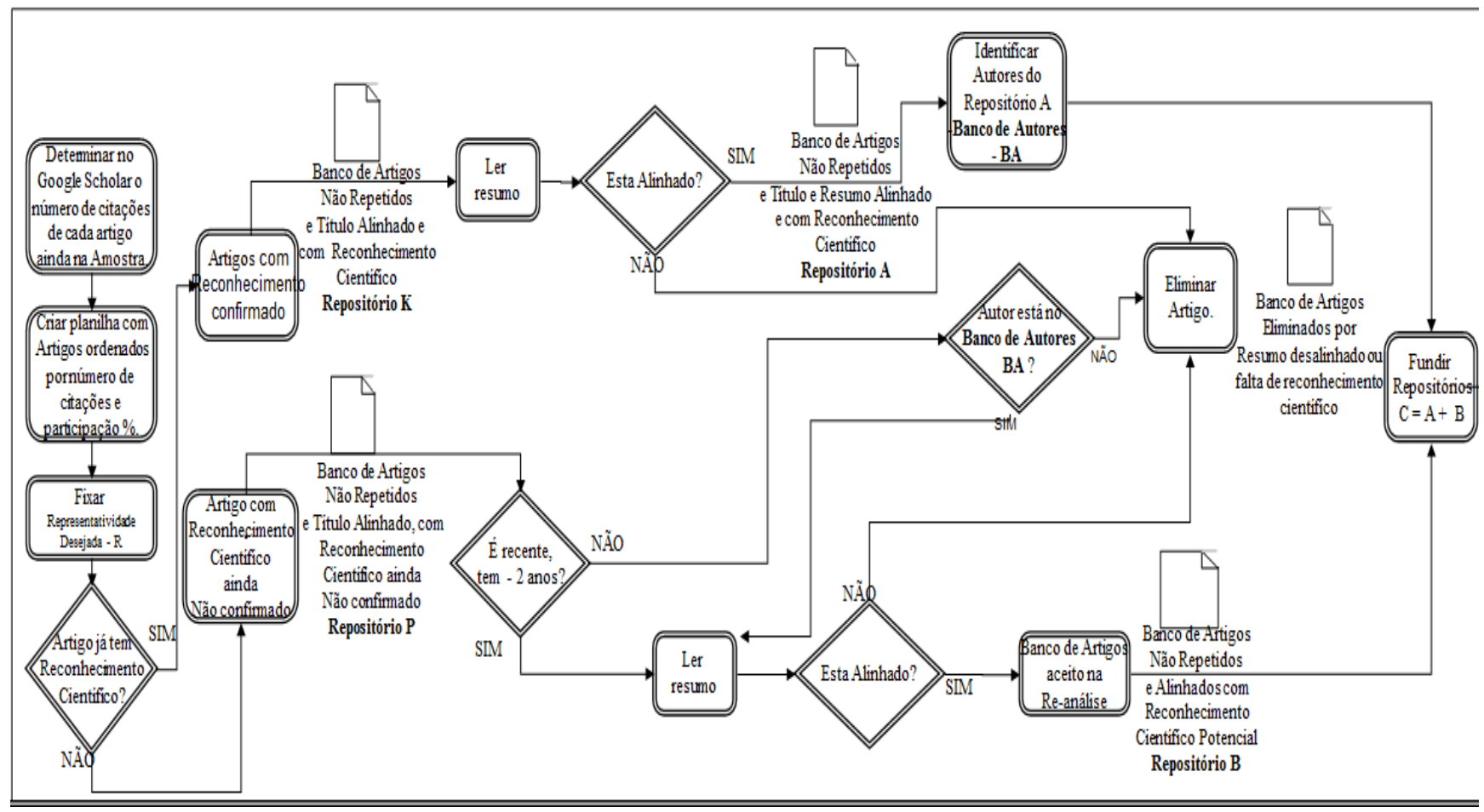

Figura 6 - Filtro do Banco de Artigos Bruto Não Repetidos e com Título Alinhado Fonte: ProKnow-C, Knowledge Development Process (2010).

Nessa etapa foram verificados os 72 artigos, estabelecendo também uma representatividade dessas publicações, ou seja, foi estabelecido um valor de corte de 85\% para os artigos mais citados, de acordo com a proposta de Ensslin et al. (2010), resultando em 10 citações ou mais. Assim, obteve-se 19 artigos que apresentaram maior número de citações e 53 artigos eliminados por apresentarem um número inferior a $85 \%$. No entanto, estes artigos serão posteriormente analisados por outros critérios e ainda podem fazer parte do portfólio final. 
Modularidade e Custos: Seleção de Um referencial para pesquisa por Meio de uma Análise

Bibliométrica

Fabrício Eduardo Henriques, Paulo Maurício Selig, Paulo Augusto Cauchick Miguel

A próxima etapa a ser realizada, ilustrada na Figura 7 , foi a da leitura dos resumos (abstracts) dos artigos selecionados para verificação do alinhamento com o tema de pesquisa.

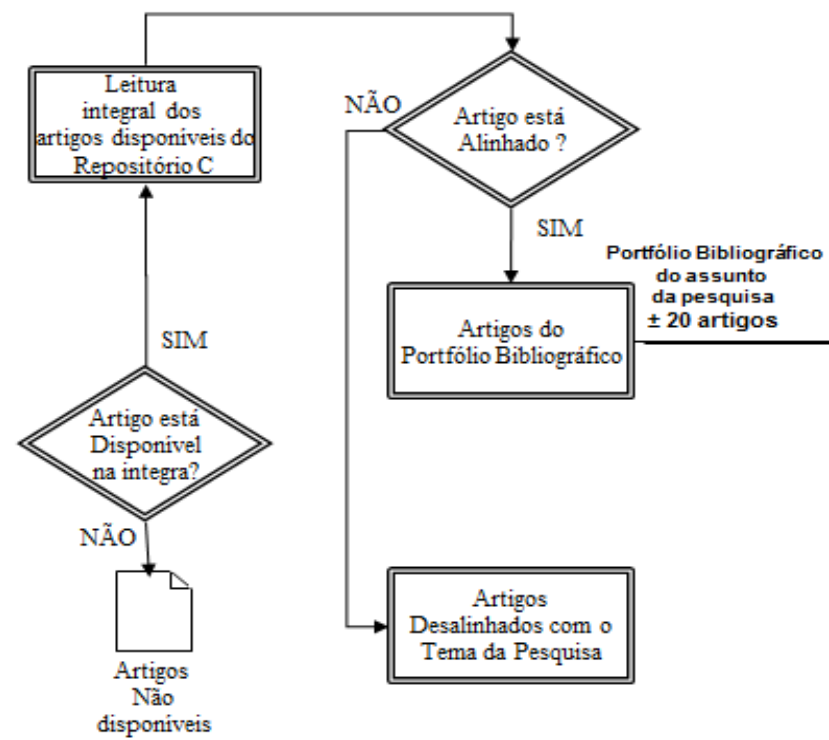

Figura 7 - Processo de filtragem pela leitura integral do artigo Fonte: ProKnow-C, Knowledge Development Process (2010).

Dos 19 artigos com maior reconhecimento científico, 11 estavam alinhados com o tema. Entretanto, 4 destes não estão disponíveis na íntegra no portal de periódicos da CAPES.

Os artigos com menos citações, verificados nas etapas mostradas na Figura 6, foram analisados usando os seguintes critérios estipulados por Ensslin et al. (2010): (i) artigos publicados há menos de 2 anos da análise, ou seja, que não tiveram possibilidades de serem muito citados ainda e, (ii) quando os artigos são publicados há mais de 2 anos, esses devem ser de autoria de algum pesquisador já presente no grupo dos 11 artigos. A partir desses critérios de re-análise dos artigos menos citados, a amostra desse grupo ficou com 20 artigos, porém 10 não disponíveis. Estes foram somados com os 7 artigos anteriormente selecionados, perfazendo assim 17 artigos a comporem o portfólio final. Como procedimento final desta etapa de construção do portfólio, foi realizada a leitura integral dos 17 artigos resultando então em 12 artigos 
Modularidade e Custos: Seleção de Um referencial para pesquisa por Meio de uma Análise

Bibliométrica

Fabrício Eduardo Henriques, Paulo Maurício Selig, Paulo Augusto Cauchick Miguel

que se alinhavam estritamente com os propósitos e temas de pesquisa. O Quadro 2 mostra a relação dos artigos.

\begin{tabular}{|c|c|c|c|}
\hline Ano & Autores & Periódico & $\begin{array}{l}\text { Qualis } \\
\text { CAPES } \\
\text { A/E3 }\end{array}$ \\
\hline 2003 & $\begin{array}{c}\text { Zhang; } \\
\text { Gershenson }\end{array}$ & Concurrent Engineering-Research and Applications & SC/B1 \\
\hline 2005 & Hopp; Xu & Manufacturing and Service Operations Management & $\mathrm{SC} / \mathrm{A} 1^{*}$ \\
\hline 2006 & Heilala & $\begin{array}{c}\text { Proceedings of the Institution of Mechanical } \\
\text { Engineers, Part B: Journal of Engineering } \\
\text { Manufacture }\end{array}$ & SC/B1 \\
\hline 2006 & Thyssen et al. & International Journal of Production Economics & A1/A1 \\
\hline 2007 & Heilala et al. & Assembly Automation & $\mathrm{SC} / \mathrm{B} 1^{* *}$ \\
\hline 2007 & Jacobs et al. & $\begin{array}{c}\text { International Journal of Operations \& Production } \\
\text { Management }\end{array}$ & $\mathrm{A} 1 / \mathrm{A} 2$ \\
\hline 2007 & Tu et al. & IEEE Transactions on Engineering Management & SC/A2 \\
\hline 2010 & Bao et al. & $\begin{array}{c}\text { Proceedings of the IEEE - Int. Conference on } \\
\text { Industrial Engineering and Engineering } \\
\text { Management (IEEM) }\end{array}$ & SC/A1 \\
\hline 2010 & Lou; Wang & $\begin{array}{c}\text { IEEE International Conference on E-Product E- } \\
\text { service and E-Entertainment (ICEEE) }\end{array}$ & SC/SC \\
\hline 2010 & Loy; Reinhart & Production Engineering & SC/SC \\
\hline 2011 & $\begin{array}{l}\text { Israelsen; } \\
\text { Jorgensen }\end{array}$ & International Journal of Production Economics & $\mathrm{A} 1 / \mathrm{A} 1$ \\
\hline 2011 & Konstantaras et al. & IMA Journal of Management Mathematics & SC/B1 \\
\hline
\end{tabular}

Quadro 2 - Relação de artigos para compor o portfólio final Fonte: desenvolvido pelos autores.

Observações: A - administração; E3 - Engenharias III da CAPES; SC - sem classificação; *JCR=2,05; **JCR $=0,655$

\section{ANÁLISE BIBLIOMÉTRICA}

A análise bibliométrica do portfólio de artigos foi realizada considerando as seguintes etapas descritas a seguir (ENSSLIN et al., 2010): (i) análise dos artigos selecionados; (ii) análise das referências dos artigos selecionados; e (iii) destaques identificados na análise dos artigos do portfólio bibliográfico e nas referências dos artigos.

\subsection{Análise dos artigos selecionados (citações)}

A análise dos artigos selecionados é dividida em três aspectos de avaliação: 
Modularidade e Custos: Seleção de Um referencial para pesquisa por Meio de uma Análise

Bibliométrica

Fabrício Eduardo Henriques, Paulo Maurício Selig, Paulo Augusto Cauchick Miguel

(i) reconhecimento pelo número de citações: composto pela verificação de citações dos artigos no Google Scholar, conforme mostrado o gráfico da Figura 8.

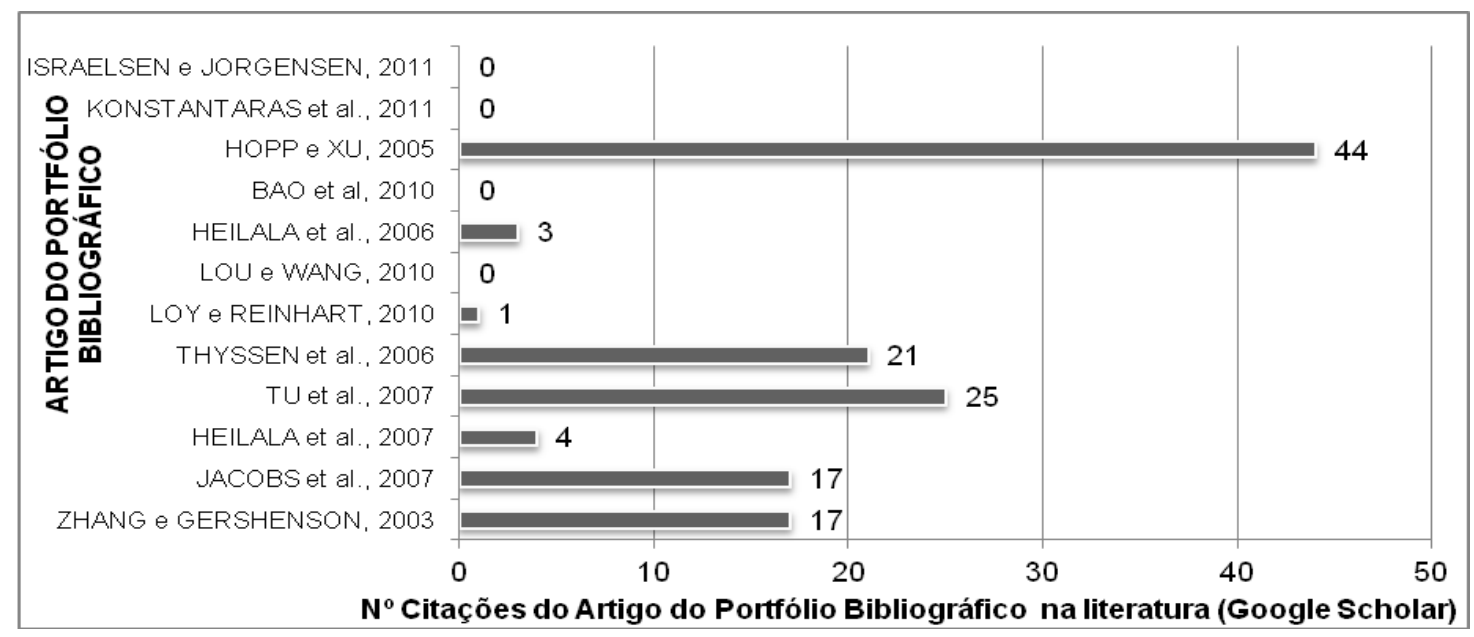

Figura 8 - Reconhecimento dos artigos por meio das citações Fonte: desenvolvido pelos autores.

Pode-se observar que o artigo com maior número de citações foi Hopp e Xu (2005), que basicamente trata de pricing na modularidade de projeto, seguido pelo trabalho de Tu et al. (2007) que trata de estimativa de custos no desenvolvimento de produtos no contexto da customização em massa.

(ii) Número de artigos por periódicos: composto pelo número de artigos em um determinado periódico. Nesse caso, somente o periódico International Journal of Production Economics teve como resultado dois artigos, ficando o restante dos periódicos com um artigo cada.

(iii) Número de artigos por autor: composto pela quantidade de autores que aparecem nos artigos. Nesse caso, cinco autores se destacam: Juhani Heilala, Jari Montonen, Kaj Helin, Poul Israelsen e Brian Jorgensen com dois artigos integrando o portfólio.

(iv) Número de palavras-chave: composta pelo número de vezes que aparecem as palavras-chave nos artigos do portfólio bibliográfico. Somente o termo 
Modularidade e Custos: Seleção de Um referencial para pesquisa por Meio de uma Análise Bibliométrica

Fabrício Eduardo Henriques, Paulo Maurício Selig, Paulo Augusto Cauchick Miguel

"modularity" aparece com frequência igual a 4, e os termos "assembly" e "modularization" duas vezes cada. O restante é citado apenas uma vez, sendo que aproximadamente um quinto são termos relacionados a custos (e.g. ABC costing; cost estimation; cost effectiveness; cost allocation; life cycle costs; etc.).

\subsection{Análise das referências dos artigos selecionados}

Para esta análise utilizam-se as referências dos artigos selecionados, com o objetivo de identificar os autores, artigos e periódicos que mais se destacam no contexto do tema de pesquisa. Foram catalogadas 369 referências em periódicos, citadas pelos 12 artigos que compõem o portfólio bibliográfico. Estas referências foram analisadas sob os seguintes parâmetros (ENSSLIN et al., 2010):

(i) Número de periódicos que publicaram os trabalhos citados nas referências: composto pela quantidade de artigos das referências bibliográficas do portfólio selecionado em um determinado periódico, conforme mostra a Figura 9.

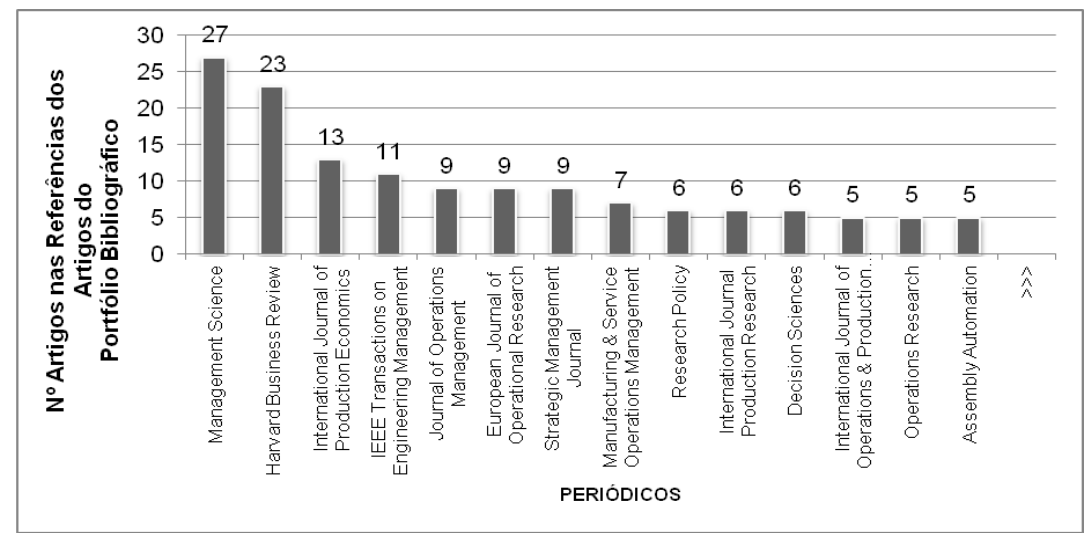

Figura 9 - Quantidade de periódicos nas referências Fonte: desenvolvido pelos autores.

Como pode ser visto na Figura 9, o periódico que mais se destaca é o Management Science (27 artigos), seguido pelo Harvard Business Review com 23 
Modularidade e Custos: Seleção de Um referencial para pesquisa por Meio de uma Análise Bibliométrica

Fabrício Eduardo Henriques, Paulo Maurício Selig, Paulo Augusto Cauchick Miguel

artigos e em terceiro o International Journal of Production Economics com 13 publicações. O IEEE Transactions on Engineering Management apresentou 11 artigos, seguido com 9 artigos pelo Journal of Operations Management, European Journal of Operational Research e Strategic Management Journal.

Nas referências dos artigos do portfólio bibliográfico, quanto ao reconhecimento em termos de citação, foi observado se os artigos do portfólio haviam sido citados nas referencias. Constatou-se que os seguintes artigos foram citados por um artigo do portfólio: Thyssen et al. (2006) e Heilala e Montonen (2006). Dado ao numero reduzido de citações dos artigos do portfólio, decidiu-se analisar o reconhecimento dos artigos pelo número de citações do autor mais citado nas referências do portfólio bibliográfico. Este resultado é mostrado na Figura 10.

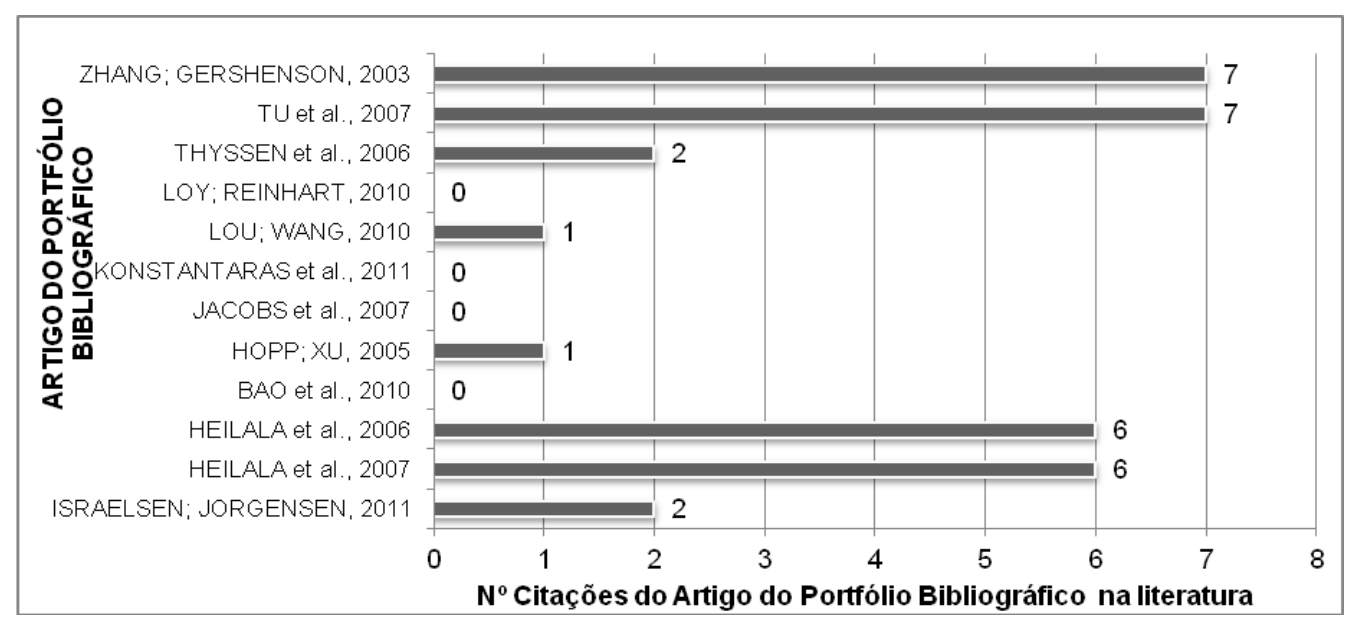

Figura 10 - Reconhecimento dos artigos do portfólio bibliográfico nas referências Fonte: desenvolvido pelos autores.

Dos 12 artigos do portfólio bibliográfico, conforme pode se observar no gráfico da Figura 10, merecem destaque quatro artigos. Os trabalhos de Zhang e Gershenson (2003) e Tu et al. (2007) tiveram 7 citações nas referências do portfólio, enquanto que os artigos de Heilala et al. (2006) e Heilala et al. (2007) foram citados por 6 artigos do portfólio bibliográfico. 
Modularidade e Custos: Seleção de Um referencial para pesquisa por Meio de uma Análise Bibliométrica

Fabrício Eduardo Henriques, Paulo Maurício Selig, Paulo Augusto Cauchick Miguel

(ii) Número de artigos por autor: composto pela quantidade de autores que aparecem nos artigos das referências bibliográficas do portfólio selecionado, conforme mostra o gráfico da Figura 11.

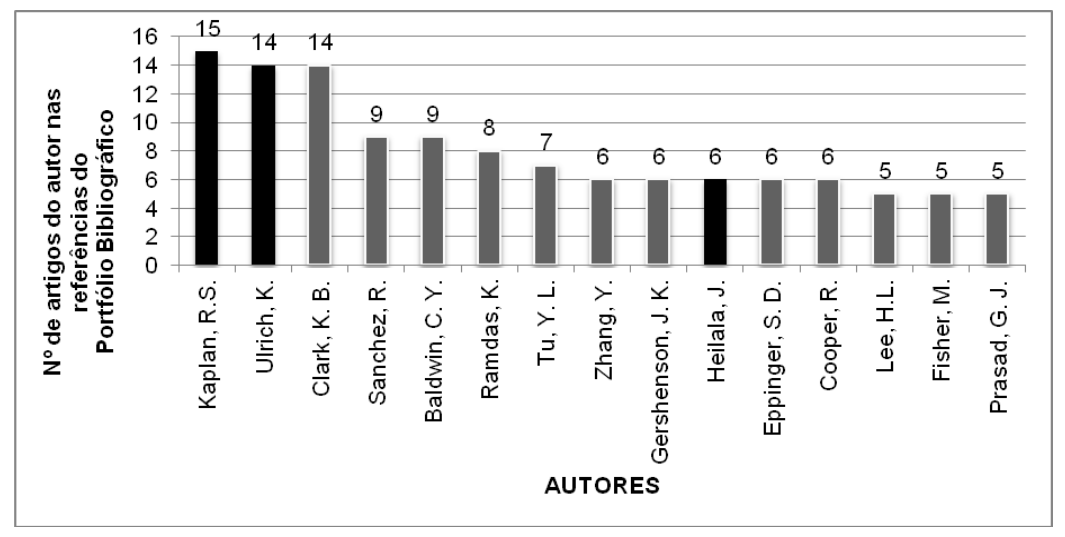

Figura 11 - Número de artigos por autor nas referências do portfólio Fonte: desenvolvido pelos autores.

Como mostrado na Figura 11, o autor que mais se destaca é Robert S. Kaplan com 15 citações nas referências do portfólio bibliográfico, seguido de Karl T. Ulrich e Kim B. Clark com 14 citações. Com 9 citações seguem os autores R. Sanchez e Carliss Y. Baldwin.

(iii) Relação da quantidade de artigos dos autores no portfólio e em suas referências: composto pela relação dos autores dos artigos do portfólio selecionado e a quantidade de artigos que possuem no portfólio e em suas referências bibliográficas, mostrado no gráfico da Figura 12. 
Modularidade e Custos: Seleção de Um referencial para pesquisa por Meio de uma Análise Bibliométrica Fabrício Eduardo Henriques, Paulo Maurício Selig, Paulo Augusto Cauchick Miguel

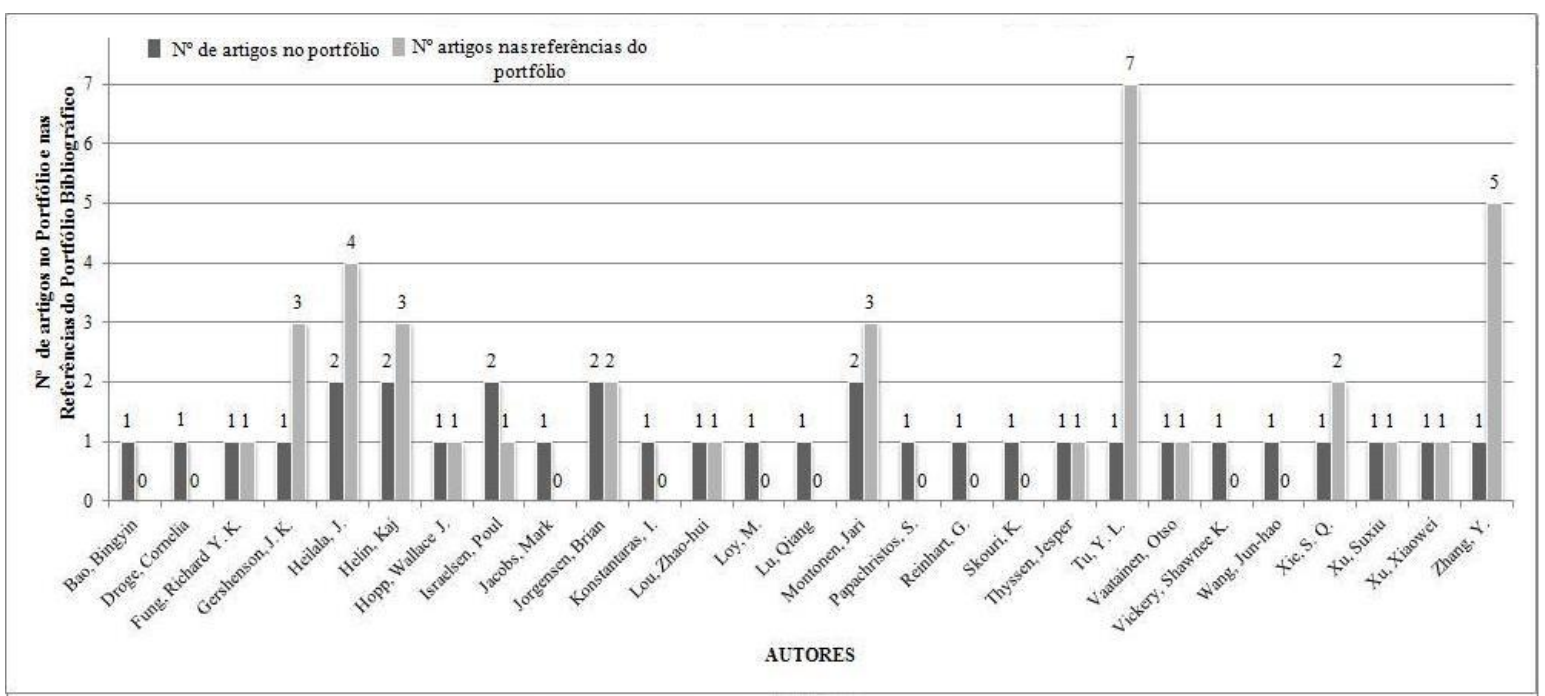

Figura 12 - Relação dos autores do portfólio com as referencias Fonte: desenvolvido pelos autores.

Pode-se observar que os autores que mais se destacam no portfólio e nas referências são: Juhani Heilala, Jari Montonen, Kaj Helin, Poul Israelsen, Brian Jorgensen, Y. Zhang, J. K. Gershenson e Y. L. Tu.

\subsection{Destaques identificados na análise dos artigos do Portfólio Bibliográfico e nas referências dos Artigos no Portfólio Bibliográfico}

Dos 12 artigos que compõem o portfólio bibliográfico representativo do tema custos em projetos modulares, e das referências encontradas nos artigos do portfólio bibliográfico foram identificados: (i) os periódicos de destaque; (ii) os artigos de destaque; e (iii) os autores de destaque. O valor de $80 \%$ do maior número obtido no eixo foi arbitrado pelos autores para determinar as fronteiras dos quadrantes. A proposta de Ensslin et al. (2010) sugere que o ponto de corte seja estabelecido, de forma a alocar cerca de $20 \%$ dos artigos na faixa de destaque, em cada um dos eixos.

A Figura 13 mostra os periódicos relevantes nos artigos do portfólio (acima da linha tracejada no eixo y) e nas referências do portfólio bibliográfico (a direita da linha tracejada no eixo x). Em relação à relevância dos periódicos, buscou-se identificar 
Modularidade e Custos: Seleção de Um referencial para pesquisa por Meio de uma Análise Bibliométrica

Fabrício Eduardo Henriques, Paulo Maurício Selig, Paulo Augusto Cauchick Miguel aqueles de destaque no portfólio e nas respectivas referências, conforme mostrado na ilustração 1.3 da Figura 2.

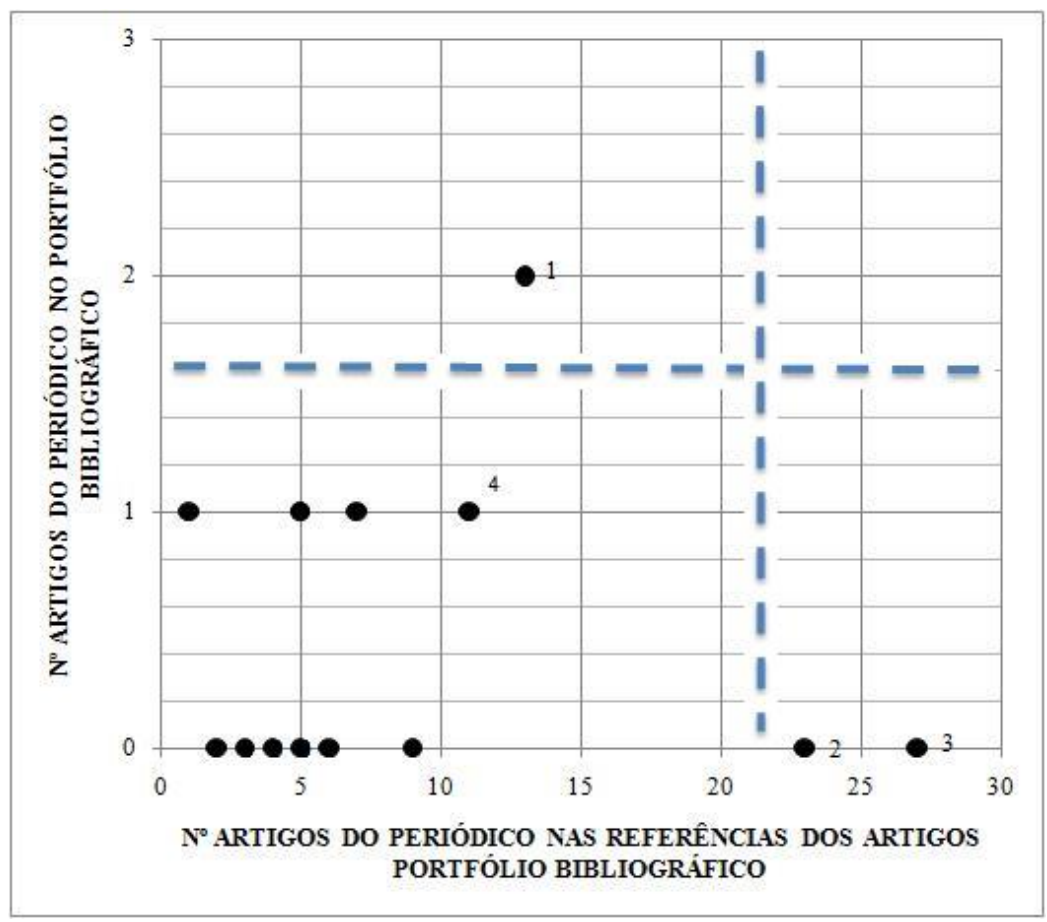

\begin{tabular}{|c|c|c|c|}
\hline 1 & International Journal of Production Economics & 2 & Harvard Business Review \\
\hline 3 & Management Science & 4 & $\begin{array}{c}\text { IEEE Transactions on Eng. } \\
\text { Man. }\end{array}$ \\
\hline
\end{tabular}

Figura 13 - Relevância dos periódicos presentes no portfólio e suas referências Fonte: desenvolvido pelos autores.

Pode se constatar que o International Journal of Production Economics foi destaque no portfólio. Os periódicos Management Science e Harvard Business Review foram destaque nas referências do portfólio. Os demais não foram destacados haja vista a sua participação em apenas um artigo do portfólio bibliográfico. Porém, os mesmos são importantes para o tema da pesquisa, em função de seu conteúdo. Não foi encontrado periódico que se destacasse tanto no portfólio como em suas referências.

Em relação ao reconhecimento dos artigos, também se buscou identificar os artigos de destaque realizados por autor de destaque. Os artigos publicados por 
Modularidade e Custos: Seleção de Um referencial para pesquisa por Meio de uma Análise Bibliométrica

Fabrício Eduardo Henriques, Paulo Maurício Selig, Paulo Augusto Cauchick Miguel

autores de destaque podem ser observados a direita da linha tracejada no eixo $\mathrm{x}$, os artigos de destaque, acima da linha tracejada no eixo y e os demais considerados como importante para a pesquisa, conforme mostrado na ilustração 2.3 da Figura 2.

A Figura 14 mostra a análise da relevância dos artigos do portfólio bibliográfico e de suas respectivas referências, considerando os aspectos anteriormente citados. A figura analisa a relevância em termos de número de citações do artigo no Google Acadêmico, comparado com o número de citações do autor mais citado do artigo nas referências do portfólio bibliográfico.

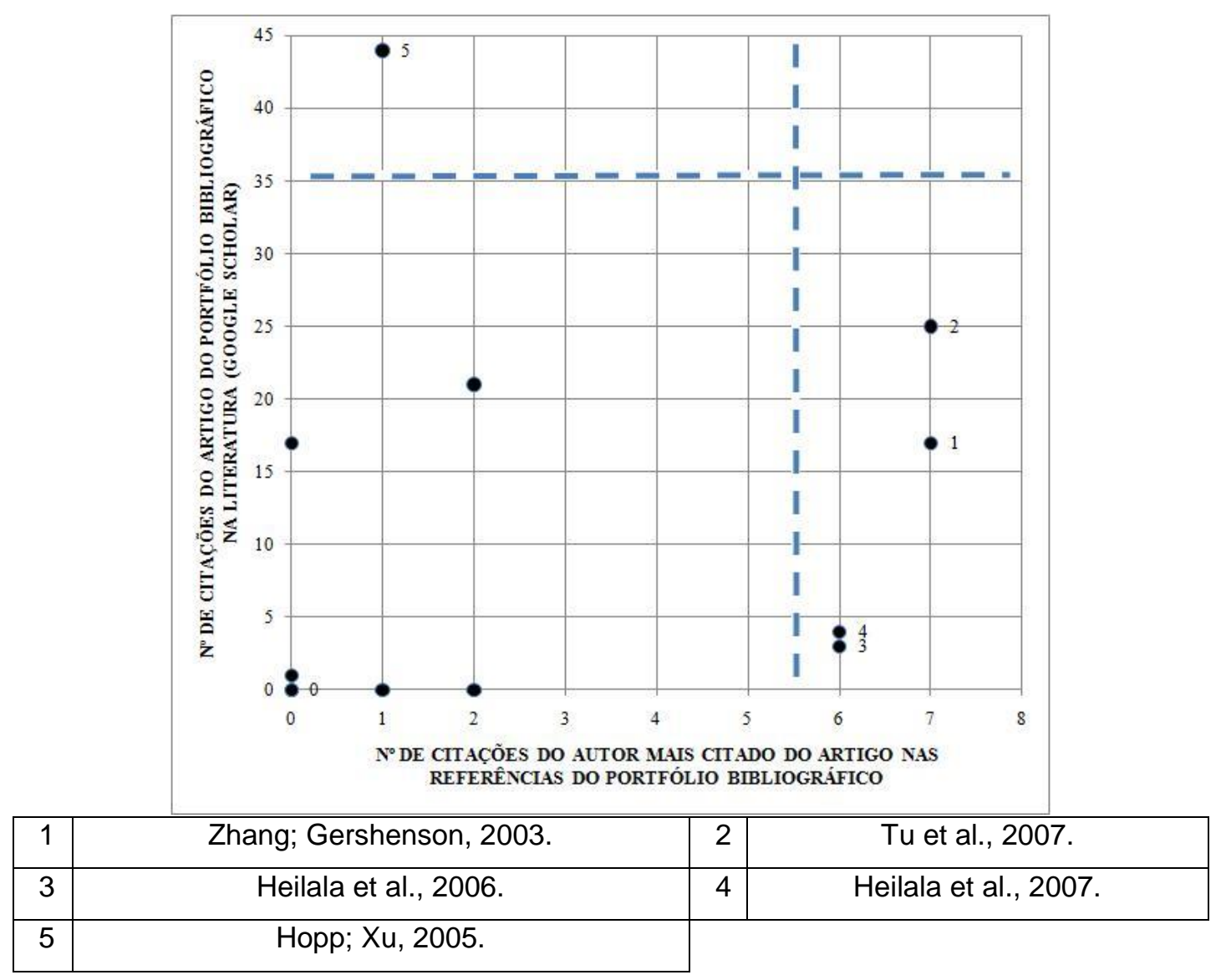

Figura 14 - Relevância dos artigos presentes no portfólio e suas referências Fonte: desenvolvido pelos autores. 
Modularidade e Custos: Seleção de Um referencial para pesquisa por Meio de uma Análise

Com base na Figura 14, os artigos de Zhang e Gershenson (2003), Tu et al. (2007), Heilala et al. (2006) e Heilala et al. (2007), foram identificados como artigos escritos por autor de destaque. O trabalho de Hopp e Xu (2005) foi considerado como artigo de destaque dentro do portfólio bibliográfico. Os demais artigos do portfólio foram classificados apenas como artigos relevantes para o tema da pesquisa, pois foram selecionados por meio da proposta de Ensslin et al. (2010) mas não se destacaram na análise bibliométrica realizada posteriormente. Não foram identificados artigos de destaque escritos por autor de destaque.

O gráfico da Figura 15 foi proposto para apresentar os autores de destaque no portfólio bibliográfico e em suas referências. A figura classifica por meio dos quadrantes separados pelas linhas tracejadas os autores em quatro categorias: autores de destaque no portfólio bibliográfico; autores de destaque dentro do portfólio bibliográfico e em suas referências; autores de destaque nas referências do portfólio bibliográfico; e autores relevantes para o tema da pesquisa, conforme mostrado na ilustração 3.3 da Figura 2. 
Modularidade e Custos: Seleção de Um referencial para pesquisa por Meio de uma Análise Bibliométrica

Fabrício Eduardo Henriques, Paulo Maurício Selig, Paulo Augusto Cauchick Miguel

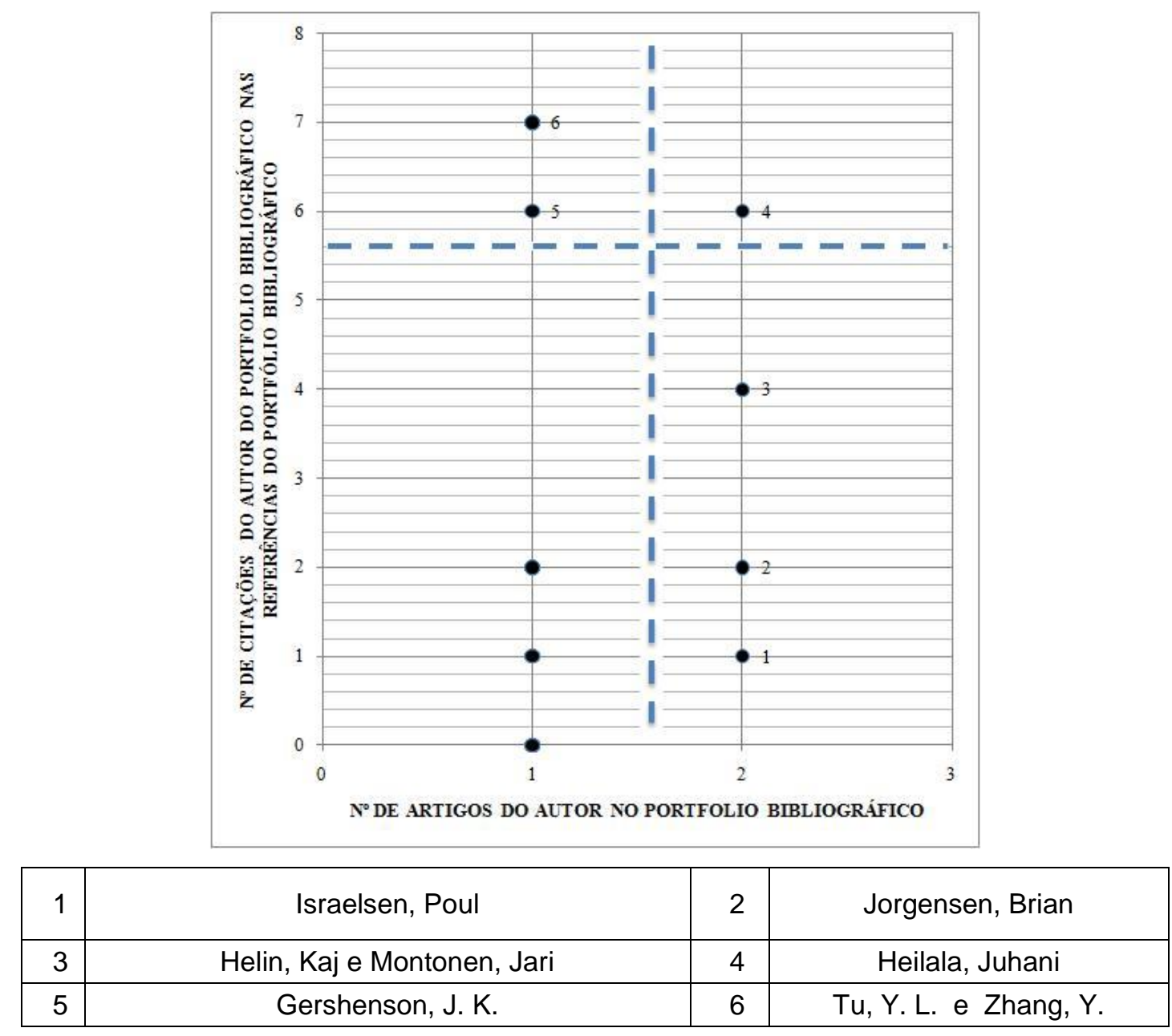

Figura 15 - Autores de destaque do portfólio bibliográfico Fonte: desenvolvido pelos autores.

Como pode ser visto os autores Poul Israelsen, Brian Jorgensen, Helin Kaj e Jari Montonen foram relacionados como autores de destaque dentro do portfólio bibliográfico. Destacaram-se nas referências do portfólio: J.K. Gershenson; Y.L. Tu; e Y. Zhang. Destacou-se dentro do portfólio bibliográfico e nas referências o autor Juhani Heilala. Todos os artigos são considerados como relevantes para a pesquisa.

Entende-se, assim, que com este trabalho foi possível identificar um corpo de artigos relevantes para a pesquisa nos temas propostos, além de fornecer para os pesquisadores o conhecimento necessário para iniciar o trabalho de pesquisa no tema modularidade com foco em custos. 
Modularidade e Custos: Seleção de Um referencial para pesquisa por Meio de uma Análise

Bibliométrica

Fabrício Eduardo Henriques, Paulo Maurício Selig, Paulo Augusto Cauchick Miguel

\section{CONCLUSÕES}

Este trabalho teve como objetivo construir, no pesquisador, o conhecimento necessário para criar as condições para que, no momento seguinte, possa pesquisar as oportunidades (lacunas) em seu tema de interesse.

O conhecimento construído consiste na evidenciação do que existe publicado com reconhecimento científico, quem está pesquisando, quais periódicos estão publicando e quais são as palavras-chave que estão sendo mais utilizadas. A partir dos objetivos de selecionar um portfólio bibliográfico relevante sobre a modularidade no contexto de custos e identificar por meio da análise bibliométrica do portfólio bibliográfico selecionado e de suas referências, os periódicos, artigos, autores e palavras-chave de destaque foram identificados e discutidos.

O processo de construção do portfólio possibilitou realizar uma análise de 5.974 artigos, culminando com um portfólio final de doze artigos alinhados com o tema. $\mathrm{Na}$ análise bibliométrica do portfólio foi evidenciado o principal periódico que aborda e publica sobre o tema e artigos reconhecidos pelo número de citações, bem como aqueles com contribuições. Na dos artigos do portfólio foi realizada a análise de suas referências, situação que permitiu evidenciar que, além dos periódicos identificados no portfólio, se destacam outros periódicos. Os autores identificados como mais citados nas referências do portfólio, são autores que tratam do tema de maneira mais abrangente, servindo como base de sustentação para uma pesquisa mais específica, a fim de complementar o portfólio bibliográfico específico de modularidade com enfoque na gestão de custos, obtido através deste processo.

No entanto, o trabalho apresenta limitações em relação ao campo amostral, pois foram utilizadas quatro bases de dados e publicações disponíveis por completo, com amplo acesso no portal de periódicos da CAPES. No entanto, os resultados mostram-se satisfatórios, mas visando sua continuidade, um trabalho futuro é expandir as bases de dados, bem como avaliar publicações nacionais. 
Modularidade e Custos: Seleção de Um referencial para pesquisa por Meio de uma Análise

Bibliométrica

Fabrício Eduardo Henriques, Paulo Maurício Selig, Paulo Augusto Cauchick Miguel

\section{REFERÊNCIAS}

BALDWIN, C. Y.; CLARK, K. B. (1997). Managing in an age of modularity. Harvard Business Review, v. 75(5):84-93.

BAO, B., XU, S.; LU, Q. (2010). Optimal modular design policy for complex systems in considering coordination costs. In: International Conference on Industrial Engineering and Engineering Management (IEEM), Macau. Proceedings of the IEE, Macau, 7-10 Dec. 2010.

CAPES - Coordenação de Aperfeiçoamento de Pessoal de Nível Superior. Disponível em http://www.capes.gov.br/. Acesso em: 10/julho/11.

ENSSLIN, L., ENSSLIN, S. R., LACERDA, R. T. O. \& TASCA, J. E. (2010). ProKnow-C, Knowledge Development Process - Constructivist. Processo técnico com patente de registro pendente junto ao INPI. Brasil.

FEITZINGER, E. e LEE, H. L. (1997). Mass customization at Hewlett Packard: The power of postponement. Harvard Business Review, 75(1):116-21.

FISHER, M.; RAMDAS, K. e ULRICH, K. (1999). Component sharing in the management of product variety: a study of automotive braking systems. Management Science, 45(3):297-315.

GIL, A. C. (1999). Métodos e Técnicas de Pesquisa Social. São Paulo, Atlas.

HEILALA, J.; MONTONEN, J.; HELIN, K. (2007). Selecting the right system - assembly system comparison with total cost of ownership methodology. Assembly Automation, 27(1):44-54.

HEILALA, J.; MONTONEN, J.; HELIN, K.; SALONEN, T.; VAAITAINEN, O. (2006). Life Cycle and Unit Cost Analysis for Modular Re-Configurable Flexible Light Assembly Systems. Proceedings of the Institution of Mechanical Engineers, Part B: Journal of Engineering Manufacture, 222(10):1289-1299.

HOPP, W. J.; XU, X. (2005). Product line selection and pricing with modularity in design. Manufacturing and Service Operations Management, 7(3):172-187.

ISRAELSEN, P.; JØRGENSEN, B. (2011). Decentralizing decision making in modularization strategies: Overcoming barriers from dysfunctional accounting systems. International Journal of Production Economics, 131(2):453-462. 
Modularidade e Custos: Seleção de Um referencial para pesquisa por Meio de uma Análise

Bibliométrica

Fabrício Eduardo Henriques, Paulo Maurício Selig, Paulo Augusto Cauchick Miguel

JACOBS, M.; SHAWNEE, K. V.; CORNELIA, D. (2007). The effects of product modularity on competitive performance: Do integration strategies mediate the relationship? International Journal of Operations \& Production Management, 27(10):1046-1068.

KONSTANTARAS, I.; SKOURI, K.; PAPACHRISTOS, S. (2011). Optimal pricing, return and modular design policy for build-to-order (BTO) products in a two parties supply chain system. IMA Journal Management Mathematics, 22(1):1-12.

KUSIAK, A. (2002). Integrated Product and Process Design: a Modularity Perspective. Journal of Engineering Design, 13(3):223-231.

LACERDA, R. T. O.; ENSSLIN, L.; ENSSLIN, S. R. (2011). A Performance Measurement Framework in Portfolio Management: A Constructivist Case. Management Decision, 49(4):648-668.

LAKATOS, E. M.; MARCONI, M. A. (2006). Fundamentos de Metodologia Científica. (6 ed.). São Paulo, Atlas.

LOU, Z. H.; WANG, J. H. (2010). The analysis of economic efficiency of modularity "design rules". In: International Conference on E-Product E-service and E-Entertainment (ICEEE), 2010, Henan, China, 7-9 Nov.

LOY, M.; REINHART, G. (2010). A new modular feeding system and its economic scope of application. Production Engineering, 4(4):357-362.

MALDONADO, M. U.; SILVA SANTOS, J. L.; SANTOS, R. N. M. (2010). Inovação e Conhecimento Organizacional: uma mapeamento bibliométrico das publicações cientificas até 2009. In: XXXIV ENCONTRO DA ANPAD, Rio de Janeiro.

MIKKOLA, J.H.; GASSMAN, O. (2003). Managing modularity of product architectures: Toward an integrated theory. IEEE Transactions on engineering management, 50(2):204-18.

MINAYO, M. C. S.; DESLANDES, S. F.; GOMES, R. (2007). Pesquisa Social: Teoria, método e criatividade. (25 ed.). Rio de janeiro, Vozes.

SUZIK, H. A. (1999). GM announces modularity project. Quality, 38(5):14.

TASCA, J.; ENSSLIN, L.; ENSSLIN, S.; ALVES, M. (2010). An approach for the strategic management process. Decision Support Systems, 33:71-85. 
Modularidade e Custos: Seleção de Um referencial para pesquisa por Meio de uma Análise

Fabrício Eduardo Henriques, Paulo Maurício Selig, Paulo Augusto Cauchick Miguel

THYSSEN, J.; ISRAELSEN, P.; JØRGENSEN, B. (2006). Activity-based costing as a method for assessing the economics of modularization-A case study and beyond. International Journal of Production Economics, 103(1):252-270.

TU, Q.; VONDEREMBSE, M. A.; RAGU-NATHAN, T. S. e RAGU-NATHAN, B. (2004). Measuring modularity-based manufacturing practices and their impact on mass customization capability: A customer-driven perspective. Decision Sciences, 35(2):14768.

TU, Y. L.; XIE, S. Q.; FUNG, R. Y. K. (2007). Product development cost estimation in mass customization. IEEE Transactions on Engineering Management, 54(1):29-40.

ZHANG, Y.; GERSHENSON, J. K. (2003). An initial study of direct relationships between life-cycle modularity and life-cycle cost. Concurrent Engineering-Research and Applications, 11(2):121-128.

Data de Submissão: 04/06/2012

Data de Aceite: 27/08/2012 